\title{
sciendo
}

\section{SOME ASPECTS ABOUT THEORETICAL STATIC RIGIDITY AND EXPERIMENTAL STATIC RIGIDITY OF A NEW ELASTIC COUPLING WITH CYLINDICAL BOLTS AND NONMETALLIC ELEMENTS}

\author{
Marilena GHIȚESCU ${ }^{1}$, Marius GHIȚESCU ${ }^{2}$, Arina MODREA ${ }^{3}$ \\ ${ }_{1,2}$ Transilvania University of Brasov \\ Heroes Boulevard no. 29, 500036, Braşov, Romania \\ ${ }^{1} \mathrm{~m}$ _ghitescu@unitbv.ro \\ ${ }^{2}$ r_ghitescu@unitbv.ro \\ ${ }^{3}$ George Emil Palade University of Medicine, Pharmacy, Science, and Technology of Targu Mures \\ 38 Gheorghe Marinescu st., no. 38, 540139, Targu Mures, Romania \\ 3arina.modrea@umfst.ro
}

\begin{abstract}
The elastic couplings are frequently used in mechanical transmissions design, to take over the radial, axial and angular misalignments and also to take over the shocks and the overloads that could appear.In this paper is presenting some aspects about the construction of couplings with bolts using non-metallic elements, e.g. rubber, having different hardness, the elements involved in torque transmission, in this case elastic elements, having also different dimensions or forms, in the way to have a good elasticity and capacity of vibration absorbtion, determining theoretical static rigidity and experimental static rigidity of a new elastic coupling with cylindrical bolts and nonmetallic elements and compare of results for these values.
\end{abstract}

Key words: elastic coupling, non-metallic elements, theoretical static rigidity, experimental static rigidity

\section{Introduction}

The elastic couplings with non-metallic elements accomplish the following functions: transmissions of rotation motion and torque moment; damping of shocks and vibrations; taking over axial, radial, angular/mixed deviations.

The paper presents aspects about the construction of couplings with bolts using non-metallic elements, e.g. rubber, having different hardness, the elements involved in torque transmission, in this case elastic elements, having also different dimensions or forms, in the way to have a good elasticity and capacity of vibration absorbtion, theoretical and experimental static rigidity of an elastic coupling with cylindrical bolts and intermediary nonmetallic elements and (see figure 1). Nonmetallic elements were mounted on the cylindrical bolts.
The torque moment is transmitted from the driver semi coupling 1 to the non-metallic elements 3 , of various shapes, through all the four cylindrical bolts 4 , fixed rigidly on the driver semi coupling 1 , and through the intermediary disc 7 to the driven semi coupling 2. The nonmetallic element has various shapes (see figure 2) and is made of various qualities of rubber.

The stresses which appear are compression in the sense of the motion, in the area in front of the bolts, crushing on the contact surface, and traction in the area defined by section B-B.

(C) 2019 Published by University Press. This is an open access article licensed under the Creative Commons Attribution-NonCommercial-NoDerivs License (http://creativecommons.org/licenses/by-nc-nd/3.0/). 

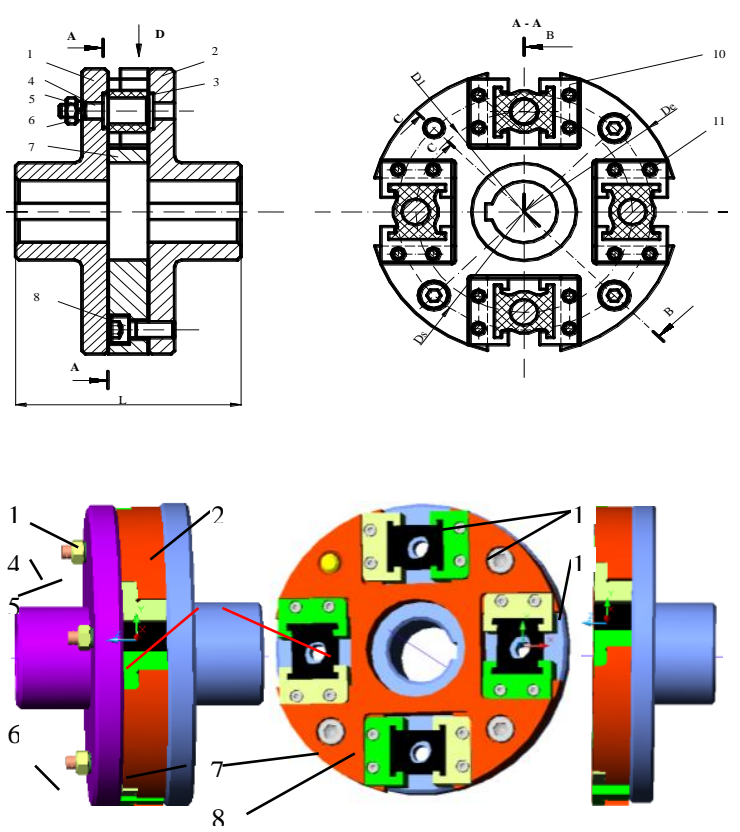

Fig. 1: Elastic coupling with intermediate nonmetallic elements and cylindrical bolts

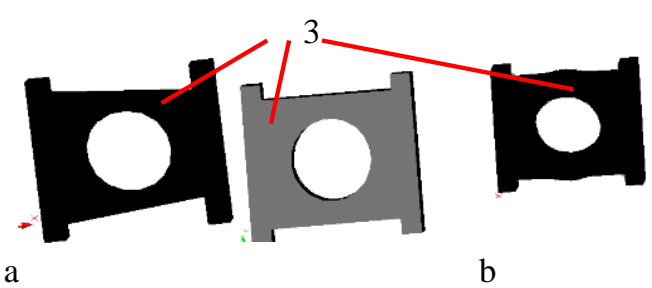

Fig. 2: The form of nonmetallic elements

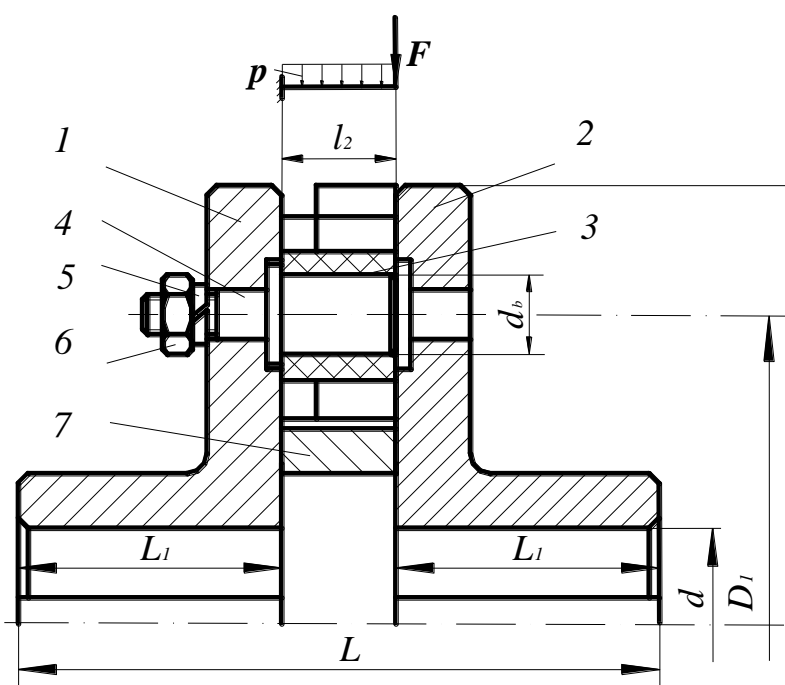

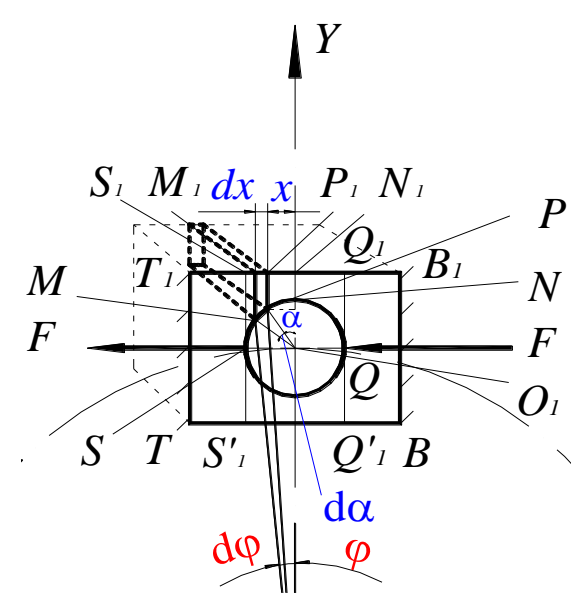
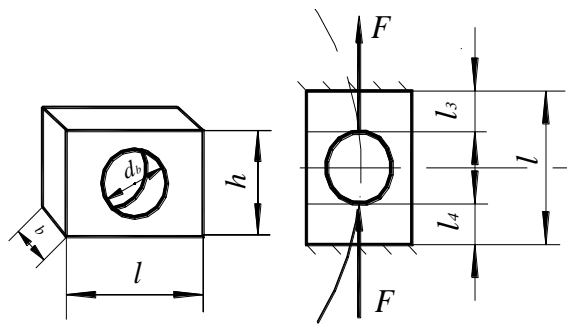

Fig. 3: The scheme of calculus of total elongation of nonmetallic

\section{Determination of theoretical static rigidity and} experimental static rigidity of a new elastic coupling with cylindrical bolts and nonmetallic elements

At determination of theoretical static rigidity of this couplings, it is draw up a simplified calculus scheme, take in consideration the following hypotheses:

- From reason symmetrical arrangement on the circle's $D 1$ diameter of four bolts, respective nonmetallic elements (see fig. 1, 2), in calculus scheme it is present just a circle quarter from circle with D1 diameter, the nonmetallic elements (1, respective 2) being dispose, one each other, in trigonometrically sense to an angle by $90^{\circ}$.

- From reason of complexity of nonmetallic element form, for calculus alleviation, the same form is considered to be a block (see fig. 3 and. fig. 4).

- The nonmetallic elements realized from various rubber qualities, the calculus's is realized in hypotheses that, for small deformations, the nonmetallic element respect Hooke's law.

- From designing of coupling, nonmetallic elements are introducing in space from two plates. For to avoid agglomeration's calculus scheme, the blocks are representing as being bleared.

It is applied of torque in the indicated sense in figure 2 and from condition of torque 
transmission $M_{t}$ through those $z$ bolts, is determine expression of force $F$,

$$
F=\frac{2 M_{t}}{z D_{1}},
$$

which load one bolt.

The force $F$ solicits to compression the portion $T T_{1} S_{1} S_{1}^{\prime}$ of nonmetallic element. The nonmetallic element may be consider that is compose from system of 3 springs (see fig. 4), connected in serie.

The spring $1 \quad\left(T T_{1} S_{1} S_{1}^{\prime}\right.$ portion $)$ is a compression spring, the spring $2\left(Q_{1} Q_{l}^{\prime} B B_{l}\right.$ portion) is traction spring and the spring 3 ( $S_{1} S_{1}^{\prime} Q_{1}^{\prime} Q_{1}$ portion) is a traction spring formed from 2 traction spring connected in parallel - $S S_{1} Q_{1} Q$, respective $S S_{1}^{\prime} Q_{1}^{\prime} Q$.

In figure 4 it was realize the following notations: $C_{1}$ represents the rigidity of compression spring 1 , $C_{2}$ - the rigidity of spring 2 , and $C_{3}$ - the rigidity of spring 3 . The portion $S_{1} B_{1} B S_{1}^{\prime}$ of nonmetallic element is consider that being formed from 2 traction springs connected in series; the portion $Q_{1} Q_{1}^{\prime} B B_{1}$ represents the spring solicited of traction to a force $F_{2}$, and portion $S_{1} S_{1}^{\prime} Q_{1}^{\prime} Q_{1}$ of nonmetallic element constitute the spring 3 solicited to traction of the same force $F_{2}$.

The spring elongation 2 of traction is determine from Hooke law

$$
\sigma_{t 2}=E \frac{f_{2}}{l_{4}}
$$

where the traction force $F_{t}=F$, aria of traction $A_{t}=b h$ and the length of traction spring in initial stare $l_{4}=\frac{l-d_{b}}{2}$, from where is determine spring elongation of traction spring 2 ,

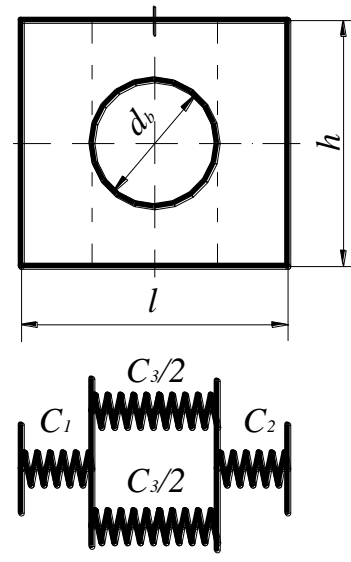

a

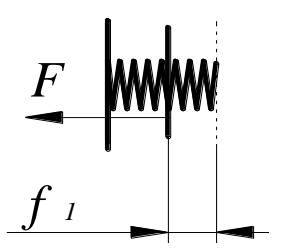

b
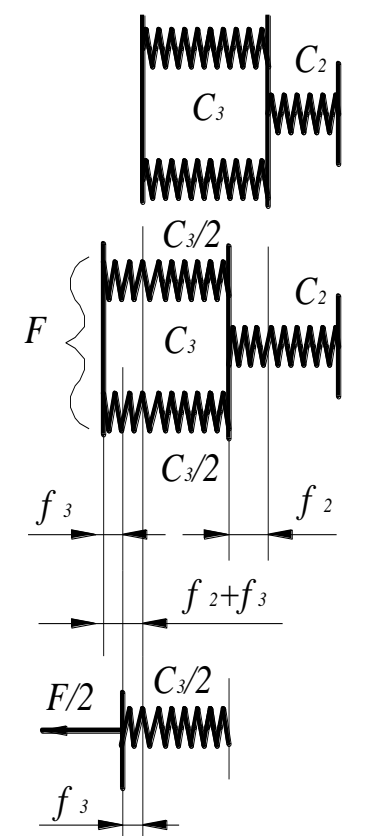

c

Fig. 4: The System of three springs from componence of non-metallic element

$$
f_{2}=\frac{F\left(l-d_{b}\right)}{2 b h E} \text {. }
$$

toward axis $O Y$, the aria of nonmetallic element deformed on the direction $P P_{1}$ is 


$$
A_{t P P_{1}}=A_{\alpha}=b\left(\frac{h}{2}-\frac{d_{b}}{2} \cos \alpha\right),
$$

and for the traction spring 3 , at $C_{3} / 2$ rigidity, solicited at traction at force $F / 2$ applies Hooke law
The rigidity of coupling $k_{r}$ is defined as the ratio of the torque to the relative rotation angle between the semi-couplings.

Therefore, the theoretical rigidity of the elastic coupling with non-metallic elements is determined using the relation

$$
\sigma_{t 3}=E \frac{\Delta f_{3}}{\Delta x}=E \frac{d f^{\prime}}{d x},
$$

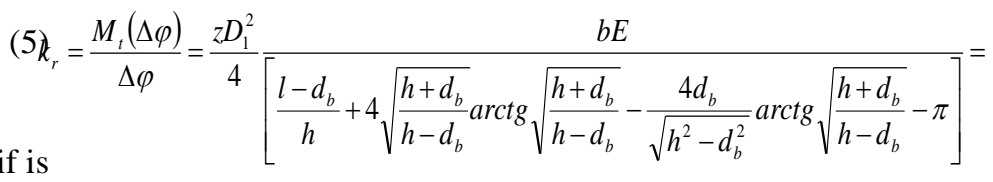

For spring 3 solicited to traction of force $F$, if is consider one element of volume $d x$, situated at distance $x$

$$
\frac{\frac{F}{2}}{b\left(\frac{h}{2}-\frac{d_{b}}{2} \cos \alpha\right)}=E \frac{d f^{\prime}}{d x}
$$

where $d x=\left(\frac{d_{b}}{2} d \alpha\right) \cos \alpha$, and the results is

$$
d f^{\prime}=\frac{F d_{b} \cos \alpha}{2 E b\left(h-d_{b} \cos \alpha\right)} d \alpha .
$$

The elongation $f_{3}$ of traction spring, by rigidity $C_{3}$ is

$$
f_{3}=2 f^{\prime}=2 \frac{F d_{b}}{E b} \int_{0}^{\frac{\pi}{2}} \frac{\cos \alpha}{h-d_{b} \cos \alpha} d \alpha
$$

and the finally expression of spring elongation is that is

$f_{3}=\frac{F}{E b}\left[4 \sqrt{\frac{h+d_{b}}{h-d_{b}}} \operatorname{arctg} \sqrt{\frac{h+d_{b}}{h-d_{b}}}-\frac{4 d_{b}}{\sqrt{h^{2}-d_{b}^{2}}} \operatorname{arctg} \sqrt{\frac{h+d_{b}}{h-d_{b}}}-\pi\right]$

The total elongation of nonmetallic element is
The theoretical calculus of static rigidity was realized for nonmetallic element from natural rubber and the form of nonmetallic element is presenting in figure 2.

Value static rigidity resulted from theoretical calculus is $k_{r}=37144,2$.

The nonmetallic elements from componence of tested elastic coupling with nonmetallic elements was realize from natural rubber and the form by type presented in figure 2 ,a.

In the frame of activities by experimental tests were realized tests of performance, respective by study of coupling behaviour in functionary.

The testing stand of prototype (fig. 5), is compose from: 1 - group drive, 2 - drive piping, 3 - body, 4 - hydraulic engine, 5 - quadrilateral mechanism, 6 - support bearing, 7 - support flange, 8 - impulse transmitter, 9 - prototype by testing, 10 - angular transducer, 11 - adjustable support, 12 - system by pretension, 13 - torsion shaft, 14 - system by measure and recording, 15 - manometer for indication of pressure, 16 - hydraulic controlling device and TER - resistive electric transducer [3]. $h+$ he measure system 14 is formed from one $h$-uhiversal recorder by pulse signal, which numbering detected pulse signals to surge generator 8, respective from electronic tensometer $\mathrm{TE}$, which indicate value of specifically deformation $\varepsilon$.

The power circuit is driving hydraulic from driver group 1, and from intermediary alimentation piping 2 is realizing alimentation of hydraulic motor 4 , which to your row, driving, from intermediary quadrilateral mechanism 5, driver shaft sustained by support bearing 6 . To support flange 7 , fixed from intermediary channeling to driver shaft end, is $-\pi$ catching with one end of tried prototype (coupling) 9, the other end of this fixed by channeling on the flange of torsion shaft 13 [3]. Thereby intermediary 
pretension system 12 , the torsion shaft 13 is fixed on the adjustable support 11, which may move after two orthogonal directions, toward to body 3 , realized prototype testing.

For determination of wished parameters, the installation is gifted with transducers (impulse transmitter, angular transducer), apparatuses by measure and control, apparatuses by visualizing of studied phenomena. For determination of different tried cycles frequency is using impulse transmitter 8 , and the impulses are counter by universal recorder NU, of measure system 14 .

Thereby action of adjuster 16 is modifying the pressure and debit to hydraulic engine, that is determine adjustment of trying cycles frequencies. For modification of amplitude of trying cycle is moving, transversal, the s support bearing 6, which has and possibility to rotation. For measure of torsion moment $M_{t}$ to which is loaded the trying prototype, on the torsion shaft 13 is applying TERresistive electric transducers, connected in bridge by measure, and thereby intermediary electronic tensometer $\mathrm{TE}$ is post value of specifically deformation $\varepsilon$. The choused functionary parameters were torsion moment to shaft of entry and torsion moment to shaft of discharge. For development in good conditions of experimental static tests was necessary preliminary activities, which were consisted in: equilibration of shafts ends of stand; equilibration of applied sensor on coupling for determination of angular deformation of coupling in static regime.

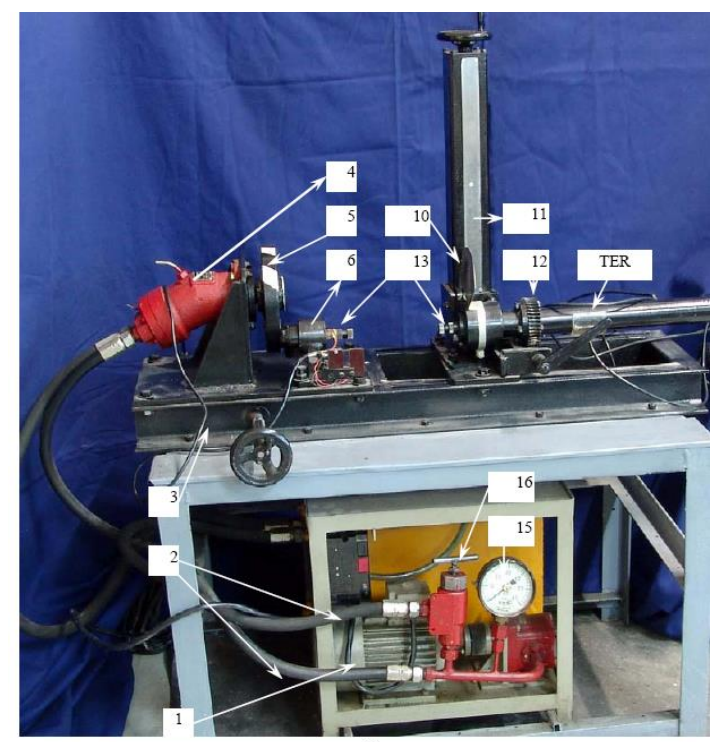

Fig. 5: Stand for static testing

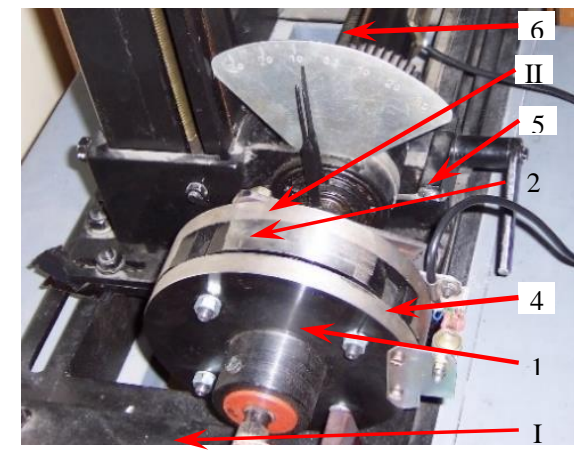

a

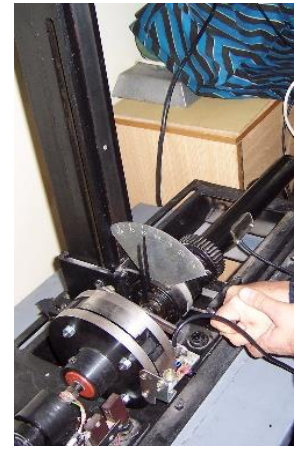

b
Fig. 6: The prototype mounted on the stand

In figure 6, a, can see the coupling mounted on the the stand and the following component elements: 1 represents driver semi coupling, 2 - driving semi coupling, 4 - metallic plate applied on the driving semi coupling, 5 - hand crank, and 6 - TER resistive electrical transducers. The entry (I) and out-put (II) shafts are collinear. Through actuating of hand crank 5 (see figure 3, b) was realized the static loading and discharge of this constructive variant of prototype, to oscilograph recorded variation of angular deformation and torsion moment to end shaft II.

Behind the processing obtained experimental dates to the oscilograph (for deformation of nonmetallic element, angle by relative rotation between semi couplings, the experimental torsion moment $M_{\text {tex }}$ to end shaft), was assigned the diagram the experimental torsion moment $M_{\text {tex }}$ to end shaft II in function by angular deformation between those semi couplings, deformation which appeared that sequel of loading and discharging with charge of coupling, obtained values being presents in table 1 .

Table 1: Experimental static rigidity of tested coupling with collinear entry - out-put shafts

\begin{tabular}{|l|l|l|c|}
\hline $\begin{array}{l}\text { Rotation } \\
\text { relative } \\
\text { angle } \\
\text { between } \\
\text { those two } \\
\text { semi } \\
\text { couplings }\end{array}$ & $\begin{array}{l}\text { Torsion } \\
\text { moment } \\
\text { to out- } \\
\text { put } \\
\text { shaft }\end{array}$ & $\begin{array}{l}\text { Experime } \\
\text { ntal Static } \\
\text { rigidity } \\
\text { of } \\
\text { coupling }\end{array}$ & $\begin{array}{c}\text { Medium } \\
\text { Experime } \\
\text { ntal static } \\
\text { rigidity } \\
\text { of } \\
\text { coupling, } \\
k_{s t}\end{array}$ \\
\cline { 1 - 3 } [degree] & [Nmm] & [Nmm/degree] \\
\cline { 1 - 2 } Experimental Static try-collinear entry - out-put \\
shafts
\end{tabular}




\begin{tabular}{|l|r|r|r|}
\hline $\begin{array}{l}\text { Discharging } \\
1,648133\end{array}$ & 44050 & 26727,21 & \\
\hline 1,592578 & 44050 & 27659,55 & \\
\hline 1,074064 & 39050 & 36357,22 & \\
\hline 0,814807 & 24050 & 29516,18 & \\
\hline 0,64 & 14050 & 21953,13 & \\
\hline 0,4 & 6700 & 16750 & \\
\hline
\end{tabular}

In table 1 is present static rigidity of tested coupling for different values of relative rotation angle between those two semi couplings, respective medium rigidity of tested coupling in case in which the entry - out-put shafts are collinear.

The Medium static rigidity of coupling is obtain with relation

$$
k_{s t}=\frac{\sum_{i=1}^{n} k_{s t i}}{n},
$$

where $n$ represents the number of dates on graphic, $k_{s t i},-$ the partial static rigidity same of each experimental dates.

Table 2: Experimental static rigidity of tested coupling with radial deviation $0,4 \mathrm{~mm}$ by entry - out-put shafts

\begin{tabular}{|c|c|c|c|}
\hline $\begin{array}{l}\text { Rotation } \\
\text { relative } \\
\text { angle } \\
\text { between } \\
\text { those two } \\
\text { semi } \\
\text { couplings }\end{array}$ & $\begin{array}{l}\text { Torsion } \\
\text { moment } \\
\text { to out- } \\
\text { put } \\
\text { shaft }\end{array}$ & $\begin{array}{l}\text { Experimental } \\
\text { static } \\
\text { rigidity of } \\
\text { coupling }\end{array}$ & $\begin{array}{l}\text { Medium } \\
\text { Experimental } \\
\text { static } \\
\text { rigidity of } \\
\text { coupling, }\end{array}$ \\
\hline [degree] & [Nmm] & \multicolumn{2}{|c|}{ [Nmm/degree] } \\
\hline \multicolumn{4}{|c|}{$\begin{array}{c}\text { Experimental static try - with radial deviation } 0,4 \mathrm{~mm} \\
\text { by entry - out-put shafts }\end{array}$} \\
\hline $\begin{array}{r}\text { Loading } \\
0,185184 \\
\end{array}$ & 6700 & 36180,33 & \multirow{9}{*}{35291} \\
\hline 0,353000 & 14050 & 39801,7 & \\
\hline 0,462514 & 19050 & 41187,91 & \\
\hline 0,555328 & 24050 & 43307,71 & \\
\hline 0,925547 & 34050 & 36789,05 & \\
\hline Discharging & & & \\
\hline 0,925547 & 34050 & 36789,05 & \\
\hline 0,837000 & 29050 & 34707,29 & \\
\hline 0,724000 & 24050 & 33218,23 & \\
\hline
\end{tabular}

The static experimental rigidity of tested coupling was calculated in function of different values of relative rotation angle between those two semi couplings and different values of torsion moment to out-put shaft, to loadind and discarching of coupling.

\section{Conclusions}

This constructive variant of prototype assure a good damping of shocks and torsion vibrations, reason of nonmetallic elements realized from different qualities of rubber. For this coupling, in function of constructive form of nonmetallic element and material of elastic nonmetallic element, it may obtain different elastic characteristics and different values of static rigidity, partial and medium rigidity.

After static equilibration of coupling, and of applied sensor on the coupling for determination of angular deformation of coupling in static regime, of equilibration of those two shafts from componence of stand by experimental test went to realizing of proposed testing.

The experimental determination was realized through progressive loading and discharging. The one between principal objectives followed was the performance level of coupling, rather, capable torsion moment to be transmitted by coupling. The deformations and solicitations from nonmetallic material are depended by charge (torsion moment $M_{t}$ ).

In case of entry and out-put shafts are collinear, the maxim angle by relative rotation between those two semi couplings is $1,64^{0}$; this value of angle corresponds of maxim deformation of nonmetallic element in static regime which is by $1,77 \mathrm{~mm}$.

From analyze through finite element method of nonmetallic elastic elements from componence of elastic coupling with cylindric bolts and nonmetallic elements, the maxim deformation of nonmetallic element realize from natural rubber was by $1,76 \mathrm{~mm}$ and it appear in circular zone where it was applied radial force distributed uniform. This deformation is appropriately by experimental deformation.

In case of entry and out-put shafts are deviation with $0,4 \mathrm{~mm}$, the maxim angle by relative rotation between those two semi couplings is $0,925547^{\circ}$; this value of angle corresponds of maxim deformation of nonmetallic element in static regime which is by $0,01615 \mathrm{~mm}$

From analyze of static rigidities of tested constructive variant of prototype, in case in the entry and out-put shafts are collinear, and value results from theoretical calculus, it is detected that experimental static rigidity value of this variant is appropriately that theoretical value if static rigidities. The experimental static rigidity in the case application of radial deviation between entry - output shafts is more big than in case in which the entry - out-put shafts are collinear. In time of experimental test of this coupling it is detected a silence functionary of prototype.

At the same, it was not detecting vibrations or radial beats, what confirms a good designing and a good execution, as well as a good equilibration of this. 


\section{References}

[1] Chişu E, et al. (1999), Intermittent mechanical couplings and with mobile contacts (Cuplaje mecanice intermitente si cu contacte mobile), Lux Libris Publishing House, ISBN 973-9240-58-5, Braşov.

[2] Radu, M. (2003), A new elastic coupling with nonmetallic elements, 3rd International Conference, „Research and Development in Mechanical Industry”, RaDMI 2003, Herceg Novi, Serbia and Montenegro, pp. 1935-1939.

[3] Radu M. (2005), Doctoral thesis - Theoretical and experimental studies as concerns couplings with nonmetallic elastic elements, Brasov.

[4] Chişu, E., Budală, A., Radu, M. (2010), Organs of machines II. Low frequency education course, Faculty of Mechanical Engineering, Specialization in Road Vehicles, "Transilvania" University of Brasov, Distance Learning Education Department (Organe de maşini II. Curs pentru învăţământ cu frecvenţă redusă, Facultatea de Inginerie Mecanică, Specializarea Autovehicule Rutiere, Universitatea „Transilvania” din Braşov, Departamentul pentru Învăţământ la Distanţă), Braşov.

[5] Radu M., Săvescu M, D. (2011), Some aspects regarding materials used in non-metallic elements construction of elastic couplings, Recent researches in Manufacturing Engineering, Published by WSEAS Press, ISBN 978-960-474-294-3, 3rd WSEAS International Conference on Manufacturing Engineering, Quality and Production Systems (MEQAPS '11), Transilvania University of Brasov
Romania, April 11-13, (ISI Thomson Reuters), pp. 211-214.

[6] Radu M., Săvescu, D. (2011), Some aspects regarding materials used in non-metallic elements construction of elastic couplings (Part II), Recent researches in Manufacturing Engineering, Published by WSEAS Press, ISBN 978-960-474-294-3, 3rd WSEAS International Conference on Manufacturing Engineering, Quality and Production Systems (MEQAPS '11), Transilvania University of Brasov Romania, April 11-13, (ISI Thomson Reuters), pp. 215-218.

[7] Săvescu D., Budală A., Ghiţescu M. (2013), Machine organs. Mechanical transmissions used in industrial technical constructions (Organe de Maşini. Transmisii mecanice utilizate în construcţii tehnice industriale), Lux Libris Publishing House, Braşov, ISBN 978-973-131-258-3, pp. 359.

[8] Ghițescu M, Ghițescu I-M., Vlase S. (2018), Some aspects about finite element modeling with bolts and nonmetallic elements of a new elastic coupling. pp. 233-237, COMAT 2018 \& eMECH 2018, ISSN $2457-8541$ ISSN-L 2457-8541. The $7^{\text {th }}$ International Conference on "Advanced Composite Materials Engineering" - COMAT 2018, The $42^{\text {th }}$ International Conference on "Mechanics of Solids, Acoustics and Vibrations" - ICMSAV 2018, The 2nd International Conference "Experimental Mechanics in Engineering" - eMECH Brasov, Romania, 25-26 Octombrie 2018, Transilvania University of Brasov, Romania. 